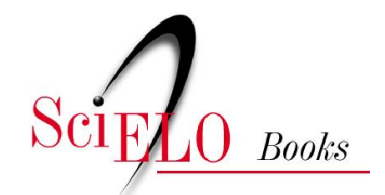

\title{
Avaliação ambiental estratégica para a gestão integrada e participativa dos recursos hídricos
}

\author{
Maria Edelcides Gondim de Vasconcelos
}

\section{SciELO Books / SciELO Livros / SciELO Libros}

VASCONCELOS, MEG. Avaliação ambiental estratégica para a gestão integrada e participativa dos recursos hídricos. In: LIRA, WS., and CÂNDIDO, GA., orgs. Gestão sustentável dos recursos naturais: uma abordagem participativa [online]. Campina Grande: EDUEPB, 2013, pp. 295-318. ISBN 9788578792824. Available from SciELO Books $<$ http://books.scielo.org $>$.

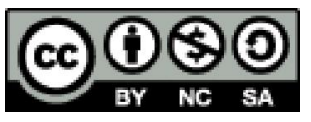

All the contents of this work, except where otherwise noted, is licensed under a Creative Commons Attribution-Non Commercial-ShareAlike 3.0 Unported.

Todo o conteúdo deste trabalho, exceto quando houver ressalva, é publicado sob a licença Creative Commons Atribuição Uso Não Comercial - Partilha nos Mesmos Termos 3.0 Não adaptada.

Todo el contenido de esta obra, excepto donde se indique lo contrario, está bajo licencia de la licencia Creative Commons Reconocimento-NoComercial-CompartirIgual 3.0 Unported. 


\title{
Avaliação ambiental estratégica para a gestão integrada e participativa dos recursos hídricos
}

\author{
Maria Edelcides Gondim de Vasconcelos
}

\section{Introdução}

O Brasil é conhecido pela abundância de recursos hídricos; o maior suprimento hídrico do planeta. Aproximadamente 13\% das águas superficiais do mundo estão no Brasil (GLEICK, 2006). São 182.633

$\mathrm{m}^{3} / \mathrm{s}$ escoando em 8,57 milhões de $\mathrm{km}^{2}$ de área. Esta aparente abundância retardou o reconhecimento da necessidade de uma gestão eficiente.

O Código de Águas, em 1934, deu início à legislação brasileira em recursos hídricos. Um modelo centralizador que deu atenção ao aproveitamento hidráulico para fins energéticos e negligenciou os demais usos.

A Lei 9.433, a Lei das Águas, em 1997, definiu um novo paradigma - gestão integrada, descentralizada e com a participação dos interessados legais: usuários, o poder público e a sociedade civil organizada.

Apesar de decorridos mais de dez anos de sua promulgação, a dimensão continental, a estrutura política, econômica e socioambiental do país contribuem para que a Lei das Águas ainda apresente grandes desafios na sua implementação.

Este trabalho propõe a introdução da Avaliação Ambiental Estratégica - AAE, um instrumento de gestão, como estratégia de superação dos desafios para uma gestão integrada e participativa. Propõe, também, identificar as perspectivas e desafios deste instrumento na Gestão dos Recursos Hídricos. 
Este estudo tem o objetivo de discutir, a partir da visão dos autores Clark (2000), Imperial College Consultants Ltd (2001), Sadler e Verheem (1996), Schreurs e Devuyst (1995), a Avaliação Ambiental Estratégica - AAE como instrumento de gestão e estratégia de superação dos desafios para uma gestão integrada e participativa, identificando os desafios deste instrumento na Gestão dos Recursos Hídricos

O artigo está estruturado da seguinte forma: inicia-se com os aspectos introdutórios e apresenta um breve histórico da gestão hídrica brasileira. Em seguida, descreve o atual modelo de gestão, elencando os desafios da Política Nacional de Recursos Hídricos. Em sequência, apresenta a Avaliação Ambiental Estratégica como instrumento de gestão, as perspectivas desse instrumento no modelo de gestão dos recursos hídricos do Brasil e analisa as compatibilidades com os princípios norteadores e os instrumentos de gestão previstos na Lei 9433/97.

\section{Um Breve histórico da gestão hídrica brasileira}

A Lei de Direito de Água do Brasil é o Código de Águas, de 10 de julho de 1934 que, apesar de seus mais de 70 anos, ainda é considerada pela Doutrina Jurídica como um dos textos modulares do Direito Positivo Brasileiro (GARRIDO, 2005).

As nossas primeiras tentativas de gestão, tendo como base a bacia hidrográfica, ocorreram na década de 70 . Iniciou-se a construção de uma nova institucionalidade que permitia abordar a gestão dos recursos hídricos considerando a sua unidade básica natural: a bacia hidrográfica.

A intenção de reformar o sistema de gestão, no entanto, tomou corpo na década de 80, quando integrantes do governo reconheceram que já era tempo de modernizar o setor que tinha funcionado, até então, baseado no Código de Águas que, embora tenha tido o marco de expandir o sistema hidroelétrico, nunca foi totalmente implementado. Com ações setoriais, o Código de Águas, em muitos de seus artigos não foi regulamentado, como é o caso dos múltiplos usos e qualidade da água (ANA, 2002a).

A Constituição Federal, em vigor, modificou o texto do Código de Águas, destacando-se a extinção do domínio privado da água, previsto em alguns casos. Todos os corpos de água, a partir de 1988, passaram a ser de domínio público. Outra modificação que merece referência foi o estabelecimento de apenas dois domínios para os corpos de água no 
Brasil: i) o domínio da união, para os rios e lagos que banham mais de uma unidade federativa ou que sirvam de fronteira entre essas unidades, ou entre o território brasileiro e países vizinhos ou deste provenham ou para o mesmo se estendam; e ii) o domínio dos estados, para águas superficiais ou subterrâneas, fluentes, emergentes e em depósito, ressalvadas as decorrentes de obras da união.

Em relação às águas subterrâneas, a Constituição Federal definiu como de domínio dos estados, sugerindo aos estados a necessidade de se articularem em casos de formações hídricas subjacentes a mais de uma unidade federada.

No final da década de 80 e, baseados na Constituição de 88, os estados de São Paulo, Rio Grande do Sul, Minas Gerais e Ceará já se mobilizavam na elaboração de legislação estadual e na criação de instâncias institucionais para o gerenciamento dos recursos hídricos. As primeiras manifestações para a utilização racional surgiram nas bacias mais degradadas, decorrentes de conflitos que impulsionaram a tomada de decisão e a organização da sociedade (COSTA, 2010).

Desde 1934, vários esforços culminaram com a promulgação, em 8 de janeiro de 1997, da Lei $n^{\circ}$ 9433, a Lei das Águas, que organiza o planejamento e a gestão dos recursos hídricos em âmbito nacional, introduzindo vários instrumentos para o setor.

\section{O atual modelo de gestão dos recursos hídricos}

O Brasil foi sempre considerado um país rico em recursos hídricos. A mudança dos índices demográficos, nos últimos trinta anos, junto ao tipo de crescimento econômico, gerou crescente pressão sobre os recursos hídricos, causando situações de escassez e de conflito em várias regiões do país. Durante este período, houve uma crescente degradação na qualidade da água em rios situados em regiões com intensa atividade industrial, de mineração e agrícola.

Para o gerenciamento dos recursos hídricos e, seguindo o espírito da Lei das Âguas, Lei 9.433, o Brasil foi dividido em regiões hidrográficas. Entendendo-se por região hidrográfica uma bacia ou grupo de bacias contíguas, na qual o principal rio escoa para o mar ou para outro país. São doze regiões hidrográficas descritas na Figura 1, onde se pode visualizar a distribuição dos recursos hídricos. Considerando a extensão territorial do Brasil de $8.574 .761 \mathrm{~km}^{2}$, a população 183,9 milhões de 
habitantes (dados do IBGE - dezembro de 2007) e uma vazão total de $182.633 \mathrm{~m} / \mathrm{s}$, pode-se ter a noção da variação da disponibilidade hídrica do país.

Figura 1 - Distribuição dos recursos hídricos por região hidrográfica

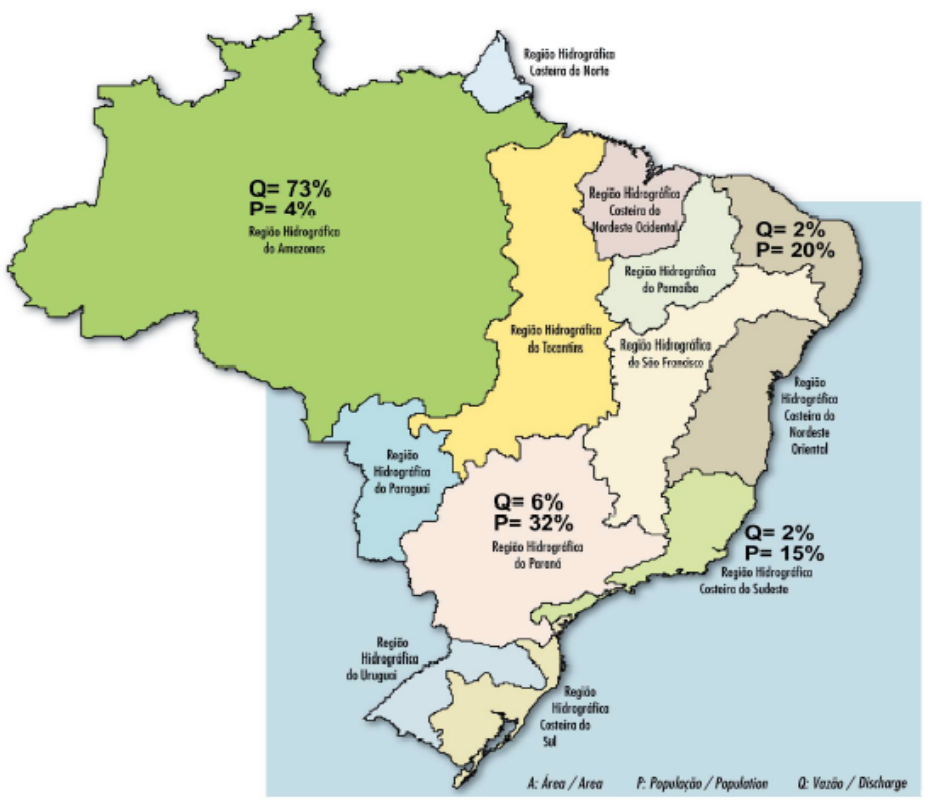

Fonte: ANA (2002b)

Pode-se observar que $73 \%$ dos recursos hídricos concentram-se na bacia hidrográfica do Amazonas, onde habita 4\% da população do Brasil. Por outro lado, 8\% dos recursos hídricos devem abastecer a região Sudeste, a mais populosa, com $47 \%$ da população do país, o que corresponde às Regiões Hidrográficas Costeiras do Sudeste e do Paraná. A Região hidrográfica Costeira do Nordeste Oriental, que concentra 20\% da população do país, conta apenas com $2 \%$ dos recursos hídricos.

\section{Política Nacional de Recursos Hídricos}

Os participantes da Conferência Internacional sobre Água e Meio Ambiente, realizada em Dublin - Irlanda, em 1992, preparatória a Conferência do Rio de Janeiro, a ECO 92, propuseram além do princípio de gestão integrada dos recursos hídricos, o reconhecimento do 
papel da mulher na gestão das águas, a valoração econômica dos recursos hídricos e os usos múltiplos, bem como, a gestão participativa, envolvendo os usuários, planejadores e o poder público em todos os níveis.

A Política Nacional de Recursos Hídricos estabeleceu um novo paradigma, a gestão integrada, descentralizada e participativa em todos os níveis da administração. Com esse novo paradigma, a gestão é compartilhada entre diferentes níveis do poder público, usuários e a sociedade civil organizada. $\mathrm{O}$ seu texto proclama os princípios básicos estabelecidos na Conferência Internacional de Dublin e praticados pelos países que avançaram na gestão de recursos hídricos.

\section{Princípios orientadores}

A Política Nacional de Recursos Hídricos tem como princípios orientadores (BRASIL. MINISTÉRIO DO MEIO AMBIENTE, 2004):

1) A bacia hidrográfica como unidade de gestão e planejamento.

Tendo-se os limites da bacia como o que define o perímetro da área a ser planejada e gerenciada, fica mais fácil fazer o confronto entre as disponibilidades e as demandas, essencial para o estabelecimento do balanço hídrico. No entanto, a bacia hidrográfica, segundo o seu conceito holístico, não exclui a tomada em consideração das águas subterrâneas de sua projeção vertical, tanto quanto deve incorporar as demandas e as relações com as bacias adjacentes e o restante do território da unidade federativa coberto apenas parcialmente pela mesma;

2) Os usos múltiplos da água.

Coloca todas as categorias usuárias em igualdade de condições em termos de acesso. No Brasil, tradicionalmente, o setor elétrico atuava como único agente do processo de gestão dos recursos hídricos superficiais, ilustrando a assimetria de tratamento historicamente conferida pelo poder central, favorecendo esse setor em detrimento das demais categorias usuárias da água. O rápido crescimento da demanda por água para outros usos fez florescer o princípio dos usos múltiplos;

3) O reconhecimento do valor econômico da água.

Fortemente indutor de seu uso racional, servindo de base para a instituição da cobrança pela utilização dos recursos hídricos, um dos instrumentos da política do setor; 
4) A gestão descentralizada e participativa.

A filosofia é a de que tudo quanto pode ser decidido em níveis hierárquicos mais baixos não será resolvido por níveis mais altos dessa hierarquia. Em outras palavras, o que pode ser decidido no âmbito regional, e mesmo local, não deve ser tratado em Brasília ou nas capitais de estados. Quanto à gestão participativa, esta constitui um método que enseja aos usuários, à sociedade civil organizada, às ONGs e a outros agentes interessados, a possibilidade de influenciar no processo da tomada de decisão da gestão da bacia hidrográfica. O comitê de bacia, com a participação dos usuários, do poder público e da sociedade civil organizada, uma vez instituído e exercendo a gestão da bacia hidrográfica, como prevê a Lei 9.433, traduz o principio básico da gestão descentralizada e participativa e enseja os outros princípios, pois será o comitê de bacia responsável pela efetivação dos demais princípios previstos na Lei;

5) Em situação de escassez, a prioridade deve ser dada para o abastecimento humano e a dessedentação de animais. Enriquece dispositivo já previsto no Código de Águas.

\section{Instrumentos de gestão}

São aspectos relevantes da Lei n ${ }^{\circ}$ 9.433/97 o estabelecimento de cinco instrumentos de gestão que refletem o atual estado da arte da gestão do uso dos recursos hídricos em todo o mundo. Os países que já os adotaram têm liderado uma verdadeira revolução no planejamento e gestão dos recursos hídricos, melhorando consideravelmente o desempenho do setor, passando a contar, cada vez mais, com água de melhor qualidade e em maior quantidade, resolvendo ou atenuando os conflitos existentes entre os usuários competidores e assegurando as bases para um desenvolvimento sustentável (GARRIDO, 2005):

1) Planos de Recursos Hídricos.

Documentos programáticos para o setor no espaço da bacia, os Planos de Bacia, um trabalho de profundidade, não só de atualização das informações que influenciam a tomada de decisão na região da bacia hidrográfica, mas que também procuram definir, com clareza, a repartição das vazões entre os usuários interessados; no espaço do estado ou distrito federal, os Planos Estaduais de recursos Hídricos e, no espaço nacional, o Plano Nacional de Recursos Hídricos. 
2) Enquadramento dos corpos de água em classes de usos preponderantes.

Extremamente importante para se estabelecer um sistema de vigilância sobre os níveis de qualidade da água dos mananciais. Aliado a isso, trata-se de um instrumento que permite fazer a ligação entre a gestão da quantidade e a gestão da qualidade da água, fortalecendo a relação entre a gestão de recursos hídricos e a gestão do meio ambiente, tomando por base a Resolução 357, de 17 de março de 2005, do CONAMA (Conselho Nacional de Meio Ambiente), que dispõe sobre classificação dos corpos de água, diretrizes ambientais para o seu enquadramento, e estabelece as condições e padrões de lançamento de efluentes. O enquadramento é ainda importante como estímulo à sociedade da bacia para a formulação de metas de qualidade a serem alcançadas, levando à tarefa do planejamento a vontade social dos usuários, das organizações não governamentais e de todos os demais agentes participantes do processo de gestão dos recursos hídricos;

3) Outorga de Direito de Uso dos Recursos Hídricos.

Mecanismo pelo qual o usuário recebe uma autorização, ou uma concessão, para fazer uso da água. A outorga de direito de uso da água, juntamente com a cobrança pelo uso da água, constitui relevante elemento para o controle do uso dos recursos hídricos, contribuindo, também, para a disciplina desse uso;

4) Cobrança pelo uso da água.

Essencial para criar as condições de equilíbrio entre a disponibilidade e a demanda, promovendo, em consequência, a harmonia entre os usuários competidores, ao mesmo tempo em que também promove a redistribuição dos custos sociais, a melhoria da qualidade dos efluentes lançados, além da formação de fundos financeiros para as obras, programas e intervenções do setor;

5) Sistema Nacional de Informações sobre Recursos Hídricos.

Destinado a coletar, organizar, criticar e difundir a base de dados relativa aos recursos hídricos, seus usos, o balanço hídrico de cada manancial e de cada bacia, provendo os gestores, os usuários, a sociedade civil e outros segmentos interessados com as condições necessárias para opinar no processo decisório. 


\section{Sistema Nacional de Gerenciamento de Recursos Hídricos}

Ressalta-se que a Lei $n^{\circ}$ 9.433/97 estabeleceu um arcabouço institucional baseado em novos tipos de organização para a gestão compartilhada do uso da água. Os seguintes organismos compõem o novo sistema de gestão:

1)Conselho Nacional de Recursos Hídricos.

Órgão mais elevado na hierarquia do Sistema Nacional de Gerenciamento de Recursos Hídricos em termos administrativos, ao qual cabe decidir sobre as grandes questões do setor, além de dirimir as contendas de maior vulto;

2) Conselhos de Recursos Hídricos dos Estados e do Distrito Federal.

Órgãos consultivos e deliberativos, aos quais cabe, na esfera de suas competências, arbitrarem, em última instância administrativa, os recursos relativos às decisões dos Comitês de Bacias Hidrográficas dos rios de domínio de seu Estado ou Distrito Federal, bem como aprovar e acompanhar os Planos Estaduais de Recursos Hídricos;

3) Comitês de bacias hidrográficas.

Tipo de organização inteiramente novo na realidade institucional brasileira, contando com a participação dos usuários, das prefeituras, da sociedade civil organizada, dos níveis de governo estadual e federal, e destinada a atuar como "Parlamento das Águas", pois é o fórum de decisão no âmbito de cada bacia hidrográfica;

4) Agências de Água.

Também uma inovação trazida pela lei, para atuarem como secretarias executivas de seu(s) correspondente(s) comitê(s), e destinadas a gerir os recursos oriundos da cobrança pelo uso da água, exercitando a administração do sistema;

5) Órgãos e entidades do serviço público federal, estaduais e municipais.

Têm relevante atuação na gestão dos recursos hídricos, devendo promover estreita parceria com os demais agentes previstos na Lei Federal n ${ }^{\circ}$ 9.433/97.

No contexto do Sistema Nacional de Gerenciamento de Recursos Hídricos, surge a promulgação da Lei n 9.984 de 17/07/2000, que criou 
a Agência Nacional de Águas - ANA. À ANA, cabe a implementação da Política Nacional de Recursos Hídricos, cuja formulação remanesceu na alçada da Secretaria Nacional de Recursos Hídricos, esta última integrante do Núcleo Estratégico do Ministério do Meio Ambiente.

A criação da ANA reflete a necessidade de separar a formulação das políticas públicas da implementação.

\section{Desafios do atual modelo de gestão dos recursos hídricos}

A implantação do Sistema Nacional de Gerenciamento de Recursos Hídricos tem sido um dos principais desafios da Política Nacional de Recursos Hídricos. Vencer este desafio requer tornar operacional o conceito de bacia hidrográfica, como unidade de planejamento e gestão, sobretudo nos rios de domínio da união, onde se sobrepõem competências tanto da união como dos estados que integram a bacia. Requer também das unidades federadas conferir prioridade, disposição e decisão política quanto à implantação e/ou fortalecimento dos Sistemas Estaduais de Gerenciamento dos Recursos Hídricos (ANA, 2002b).

O fortalecimento dos órgãos gestores, a ampliação da articulação da União com os Estados, o esclarecimento do papel dos comitês, a representatividade nos comitês como entes de estado, consolidar efetivamente a participação dos municípios e a garantia de recursos são desafios urgentes a serem vencidos, necessários à efetiva implantação do Sistema Nacional de Gerenciamento de Recursos Hídricos.

O modelo de gestão dos recursos hídricos no Brasil é, ainda, um processo em construção. Apenas a existência legal de instrumentos institucionais, técnicos e econômicos de gestão não tem garantido a implantação nem o funcionamento pleno do Sistema Nacional de Gerenciamento de Recursos Hídricos, considerando os princípios básicos da Lei 9.433.

Os grandes desafios no processo de implantação do sistema de gestão estão na gestão compartilhada, no nível de bacia, com o Comitê de Bacia assumindo o seu papel de gestor. A criação do Comitê de Bacia, por sua vez, depende do grau de mobilização da sociedade civil na sua área de abrangência. No entanto, os conflitos pelo uso da água têm impulsionado a criação e o amadurecimento de Comitês de Bacias e não a consciência de que a água é um bem limitado e que o uso racional é prioritário. 
Assegurar o princípio básico da gestão integrada, descentralizada e participativa é contar com Comitês de Bacias que planejam e gerenciam, utilizando de forma efetiva todos os instrumentos de gestão previstos na Lei das Águas. O grande desafio do modelo de gestão é assegurar integração e efetiva participação dos reais interessados: os usuários, o poder público e a sociedade civil.

\section{Avaliação ambiental estratégica}

Avaliação Ambiental Estratégica - AAE tem sido reconhecida como uma forma de avaliação ambiental que pode assistir gerentes e líderes em decisões de Políticas, Planos e Programas. Tomadores de decisão, em várias partes do mundo, têm adotado a $\mathrm{AAE}$, pois consideram que as decisões através da AAE têm a capacidade de influenciar na sustentabilidade do ambiente e prover uma saudável, integrada e sustentável estrutura de planejamento.

Procura-se prever as consequências de ações antes que elas aconteçam, quando efeitos negativos podem ser previstos ou evitados, ou as ações são modificadas, ou então aceitas as consequências.

Avaliação Ambiental Estratégica é um processo com o objetivo de assegurar que significantes efeitos ambientais surgidos de políticas, planos e programas sejam identificados, avaliados, mitigados, comunicados aos tomadores de decisão, monitorados e que oportunidades de participação, para o público envolvido, sejam providenciadas.

Entre os benefícios da AAE, podemos incluir: i- Dar suporte à sustentabilidade do desenvolvimento; ii- Fornecer bases evidentes para decisões estratégicas; iii- Desencadear outros processos como Avaliação de Impacto Ambiental de projetos individuais de desenvolvimento.

AAE é um instrumento que pode ser usado em uma variedade de situações. Uma particular forma foi introduzida pela União Europeia através da Diretiva 2001/42/EC, o que requereu que autoridades nacionais, regionais e locais dos Estados Membros desenvolvessem estratégicas avaliações ambientais em certos planos e programas. 


\section{Conceito, objetivo e origem da AAE}

Segundo Sadler e Verheem (1996), Avaliação Ambiental Estratégica - AAE é um sistemático processo que prevê e avalia as consequências ambientais de POLÍTICAS, PLANOS ou PROGRAMAS.

A AAE tem o objetivo de introduzir os aspectos ambientais e socioeconômicos em níveis mais estratégicos da tomada de decisão, antes que a implementação da POLÍTICA chegue ao nível de PROJETO

A evolução do processo de avaliação ambiental está constantemente avançando em resposta a novas necessidades e experiências no seu processo de implementação. A evolução pode ser assim resumida:

Quadro 1 - Evolução do processo de avaliação ambiental

\begin{tabular}{|l|l|}
\hline Período & Características da avaliação \\
\hline Antes de 1970 & $\begin{array}{l}\text { Análise de Custo x Beneficio; } \\
\text { Centrada em aspectos econômicos. }\end{array}$ \\
\hline 1970 a 1980 & $\begin{array}{l}\text { Análise centrada no ambiente natural; } \\
\text { Interação humana ignorada. }\end{array}$ \\
\hline 1980 a 1985 & $\begin{array}{l}\text { Avaliação dos impactos sociais e econômicos; Participação do } \\
\text { público; } \\
\text { Processo multidimensional. }\end{array}$ \\
\hline 1985 a 1990 & $\begin{array}{l}\text { Avaliação com atenção ao monitoramento e a auditoria; } \\
\text { Reconhecida a necessidade de avaliar impactos cumulativos. }\end{array}$ \\
\hline Após 1990 & $\begin{array}{l}\text { Reconhecimento da necessidade de uma avaliação em nível mais } \\
\text { estratégico. }\end{array}$ \\
\hline
\end{tabular}

Fonte: adaptado de Mun (2004)

A origem da Avaliação Ambiental Estratégica está, portanto, nas intrínsecas limitações da Avaliação de Impacto Ambiental (AIA) que é consubstanciada pelo EIA - RIMA, o Estudo e o respectivo Relatório de Impacto Ambiental.

A AIA prevê e avalia os efeitos ambientais no nível de Projeto, aparecendo, portanto, tardiamente no processo de tomada de decisão, quando muitas das decisões já foram tomadas, nas fases de política, plano e programa. A AIA apresenta também ineficiência na consideração de efeitos cumulativos, em tempo e escala. 
A AAE tem origem na necessidade de implementação de um instrumento de avaliação antes que a AIA, em nível de Projeto, seja realizada.

Figura 2 - Processo integrado da AAE e AIA

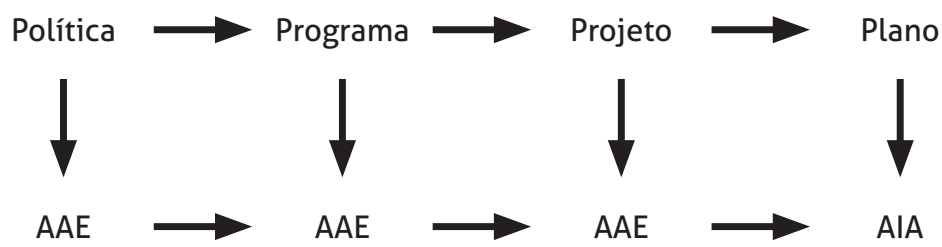

A AAE e a AIA num processo integrado e complementar:

- Enfocam atenção no mais apropriado estágio para considerar particular impacto;

- Apresentam procedimentos similares;

- AAE simplifica a AIA tornando mais fácil e em alguns casos desnecessária;

- AAE fornece dados básicos para AIA, reduzindo custos;

- AAE pode esclarecer condições ambientais para aprovação de Projetos;

- AAE filtra os Projetos mais prejudiciais, retirando a necessidade de detalhar EIAs caros e controvertidos;

- Levam a decisões de maior credibilidade;

- AAE e AIA num processo de planejamento complementar e integrado melhoram a tomada de decisão através de decisões integradas;

- Embora baseadas em princípios comuns, a AAE e AIA quando comparadas, apresentam diferenças características de cada processo: 
Quadro 2 - Comparação dos Instrumentos de Avaliação AAE e AIA

\begin{tabular}{|l|l|}
\hline \multicolumn{1}{|c|}{ Avaliação de Impacto Ambiental } & \multicolumn{1}{|c|}{ Avaliação Ambiental Estratégica } \\
\hline $\begin{array}{l}\text { É reativo para uma proposta de de proativo e informa propostas de } \\
\text { desenvolvimento }\end{array}$ & $\begin{array}{l}\text { É } \\
\text { desenvolvimento }\end{array}$ \\
\hline $\begin{array}{l}\text { Avalia o efeito de um proposto } \\
\text { desenvolvimento no meio ambiente }\end{array}$ & $\begin{array}{l}\text { Avalia o efeito do meio ambiente } \\
\text { nas necessidades e oportunidades do } \\
\text { desenvolvimento }\end{array}$ \\
\hline É direcionado para um projeto específico & $\begin{array}{l}\text { É direcionado a áreas, regiões ou setores de } \\
\text { desenvolvimento }\end{array}$ \\
\hline Tem começo e fim bem definidos & $\begin{array}{l}\text { É um contínuo processo objetivando prover } \\
\text { informação no tempo certo }\end{array}$ \\
\hline $\begin{array}{l}\text { Avalia impactos e benefícios do projeto } \\
\text { específico }\end{array}$ & $\begin{array}{l}\text { Avalia impactos cumulativos e } \\
\text { identifica implicações e aspectos para a } \\
\text { sustentabilidade do desenvolvimento }\end{array}$ \\
\hline É focado na mitigação de impactos & $\begin{array}{l}\text { É focado na manutenção de um determinado } \\
\text { nível de qualidade ambiental }\end{array}$ \\
\hline
\end{tabular}

Fonte: adaptado de CSIR (1996)

Embora os dois instrumentos de avaliação sejam utilizados para a tomada de decisão, a diferença está no tipo de decisão com a qual cada uma das avaliações está ligada.

A Avaliação de Impacto Ambiental é associada a decisões de projeto; normalmente decisões finais antes que uma atividade ou uma obra possa ser iniciada. Existem decisões detalhadas, principalmente sobre locação e design do projeto e sobre medidas mitigadoras mais do que de prevenção de impactos. Possíveis alternativas, no estágio de projeto, são frequentemente limitadas a pequenas variantes.

A Avaliação Ambiental Estratégica, por outro lado, é associada a decisões em níveis mais estratégicos. $\mathrm{O}$ sucesso da AAE está em produzir uma avaliação significativa, mais rápida, sem perda de tempo e dinheiro em detalhadas avaliações. O propósito da AAE é melhor levar em consideração as questões ambientais e fazer o processo de decisão mais transparente por meio da consulta e participação.

Embora baseadas em princípios comuns e apresentando similaridades de processos, existem diferenças de procedimento.

O desenvolvimento das Políticas, Planos e Programas são processos de longo prazo incluindo muitas rodadas de consulta. Portanto, o gerenciamento do procedimento, no nível da AAE, é bem diferente do desempenhado pela AIA. Em comparação com a AIA, AAE é um processo com mais ciclos de realimentação. 


\section{Desafios para introdução e implementação da AAE}

O primeiro desafio é definir, exatamente, os significados e chegar a um entendimento geral. A clareza de significados deve evitar a conotação de um processo vago e obscuro (SCHREURS; DEVUYST, 1995). O sucesso da Avaliação Ambiental Estratégica está na precisão e exequibilidade. Outro desafio é de ordem institucional. As instituições, em geral, não são coesivas o bastante para trabalhar no nível estratégico. Os desafios metodológicos da introdução e implementação da AAE dizem respeito:

Dados e informações - Os dados e as informações alimentam análises. Análises raramente têm todos os dados que os líderes acreditam precisar para a tomada de decisão. Mesmo com os dados existentes, as instituições não têm a cultura de coordenar a partilha de dados e informações. No nível estratégico, os dados são mais escassos, a interpretação de menor aceitação pelos tomadores de decisão (CLARK, 2000).

Incerteza - Existe sempre alguém desfavorável em arriscar tomar decisões ou permitir que decisões sejam tomadas sem uma virtual certeza. A incerteza aumenta considerando as correlações com presentes e futuros desenvolvimentos.

Complexidade - $\mathrm{O}$ processo de AAE envolve a avaliação da cumulação de impactos, o que resulta numa maior complexidade de interpretação e uma grande variedade de alternativas, resultando num processo de interpretação muito mais complexo.

Capacidade, conhecimento e habilidade - Preparar a avaliação de impacto, em nível de projeto, requer habilidades avançadas e um pool de profissionais qualificados. Para a avaliação estratégica, pela complexidade, além do necessário conhecimento dos profissionais envolvidos, exigi-se certa capacidade e habilidade para a condução de um processo eficiente, transparente e que apresente resultados de credibilidade.

Procedimento - Os grandes desafios de procedimento da AAE estão relacionados à coordenação entre autoridades, à definição dos momentos apropriados de comunicação e participação pública e da consideração dos resultados da avaliação, no processo de tomada de decisão. 


\section{Critérios para um bom desempenho da AAE}

Avaliação Ambiental Estratégica tem se tornado um debate caloroso e a Associação Internacional de Avaliação de Impacto - IAIA procurou fornecer um profissional produto no assunto, para assistir seus membros.

Este conjunto de critérios foi desenvolvido por Verheem (2002) da Comissão de EIA de Netherlands, em consulta com membros da seção de Avaliação Ambiental Estratégica da IAIA e através de discussão em Workshop especial ocorridos em 1998, 1999 e 2000, durante as conferências anuais da IAIA.

Os critérios de desempenho foram usados e testados na prática por membros da IAIA e endossados pelo Conselho de Diretores da IAIA em novembro de 2001, objetivando prover uma orientação geral de como construir um eficiente processo de Avaliação Ambiental Estratégica e avaliar a eficiência dos processos existentes.

Um processo de Avaliação Ambiental Estratégica - AAE de boa qualidade, segundo a IAIA informa aos planejadores, aos tomadores de decisão e ao público afetado decisões estratégicas sustentáveis; facilita a busca pela melhor alternativa; e assegura um processo de tomada de decisão democrático.

$\mathrm{O}$ processo AAE de boa qualidade deve apresentar, segundo Verheem (2002), as seguintes características:

- Integração: Assegurar uma apropriada avaliação do impacto de todas as decisões estratégicas relevantes para o alcance da sustentabilidade do desenvolvimento. Direcionar as inter-relações entre os aspectos biofísicos, sociais e econômicos. É um processo que acontece em etapas ligadas para políticas, planos e programas, em relação aos setores relevantes e a regiões e, onde for apropriado, para Avaliação de Impactos Ambientais - AIA- de projetos.

- Sustentabilidade: Facilitar a identificação de opções de desenvolvimento e propostas alternativas mais sustentáveis.

- Foco: Prover suficiente, confiável e útil informação para o plano de desenvolvimento e a tomada de decisão. Concentrar em aspectos-chave da sustentabilidade do desenvolvimento. 
Adequar-se às características do processo de tomada de decisão. Eficiente em custo e tempo.

- Responsabilidade: Fornecer subsídios para as instituições líderes, para que decisões estratégicas responsáveis sejam tomadas. Ser desenvolvido com profissionalismo, rigor, honestidade, imparcialidade e equilíbrio. Ser objeto de independente checagem e verificação. Documentar e justificar como aspectos de sustentabilidade foram levados em consideração na tomada de decisão.

- Participação: Informar e envolver o público interessado e afetado e os órgãos governamentais em todo o processo de tomada de decisão. Explicitamente direcionar as sugestões e interesses dos envolvidos na documentação e tomada de decisão. Ter informações claras e de fácil entendimento e assegurar suficiente acesso a toda informação relevante.

- Interação: Assegurar disponibilidade dos resultados da avaliação, no tempo suficiente para influenciar o processo de tomada de decisão e fornecer ideias para futuros planejamentos. Fornecer suficiente informação de impactos reais na implementação de decisões estratégicas, para julgar se esta decisão deve ser alterada e prover a base para futuras decisões.

\section{AAE Na gestão dos Recursos hídricos}

A Avaliação Ambiental Estratégica - AAE - aplica-se a áreas objeto de Políticas, Planos ou Programas passíveis de substancial impacto ambiental. Incluindo-se os tradicionais setores da gestão ambiental: energia, agricultura, indústria, turismo, transporte, recursos hídricos.

Analisando os princípios da Lei das Águas, pode-se verificar a compatibilidade e/ou semelhança com os princípios preconizados pela Avaliação Ambiental Estratégica. O Quadro 3 relaciona os princípios da Lei 9.433/97 e da AAE, e os resultados esperados quando a avaliação for aplicada à gestão dos recursos hídricos. 
Quadro 3 - AAE na Gestão dos Recursos Hídricos

\begin{tabular}{|c|c|c|}
\hline Princípios da Lei 9433/97 & AAE & AAE na GRH \\
\hline $\begin{array}{c}\text { Bacia Hidrográfica como } \\
\text { unidade de planejamento }\end{array}$ & Avalia impactos cumulativos & $\begin{array}{c}\text { Considerar os impactos } \\
\text { cumulativos significa } \\
\text { maior integração e } \\
\text { sustentabilidade }\end{array}$ \\
\hline Múltiplos usos & $\begin{array}{c}\text { Avalia aspectos } \\
\text { socioeconômicos e } \\
\text { ambientais }\end{array}$ & $\begin{array}{c}\text { Decisões mais sustentáveis } \\
\text { em situação de conflito }\end{array}$ \\
\hline Outorga e cobrança & $\begin{array}{c}\text { Avalia aspectos } \\
\text { socioeconômicos e } \\
\text { ambientais, participação e } \\
\text { transparência }\end{array}$ & $\begin{array}{c}\text { Outorga e cobrança com } \\
\text { maior sustentabilidade e } \\
\text { justiça socioambiental }\end{array}$ \\
\hline $\begin{array}{c}\text { Gestão Descentralizada e } \\
\text { participativa }\end{array}$ & $\begin{array}{c}\text { Participação e transparência } \\
\text { Decisões e intervenções } \\
\text { transparentes e } \\
\text { participativas }\end{array}$ \\
\hline
\end{tabular}

Adaptado de Vasconcelos (2005)

O primeiro princípio da lei 9.433 é a adoção da bacia hidrográfica como unidade de planejamento. Tendo-se os limites da bacia como o que define o perímetro da área a ser planejada, fica mais fácil fazer o confronto entre as disponibilidades e as demandas, essencial para o estabelecimento do balanço hídrico.

Por outro lado, considerando os impactos cumulativos resultantes do mesmo tipo de projeto e a sinergia resultante da interação entre impactos, a bacia hidrográfica, como unidade de planejamento é considerada ambiente favorável para o sucesso da avaliação dos impactos cumulativos, uma vez que tem seus limites, naturalmente, definidos (CEARC, 1988).

Os usos múltiplos da água colocam todas as categorias usuárias em igualdade de condições em termos de acesso. $\mathrm{O}$ rápido crescimento da demanda por água, para os diversos setores, tem levado a conflitos. A avaliação de aspectos ambientais e socioeconômicos, preconizados pela AAE, deverão contribuir para decisões mais sustentáveis, integradas e com maior justiça socioeconômica e ambiental, na solução de conflitos.

Considerando o princípio da outorga e o reconhecimento do valor econômico da água, servindo de base para a instituição da cobrança pela utilização dos recursos hídricos, os princípios da AAE convergem para fornecer, de forma responsável, subsídios para a outorga e a definição de uma cobrança justa e sustentável. 
O princípio da gestão descentralizada e participativa constitui um método que enseja aos usuários, à sociedade civil organizada, às ONGs e outros agentes interessados a possibilidade de influenciar no processo de tomada de decisão sobre investimentos e outras formas de intervenção na bacia hidrográfica.

O princípio da descentralização é totalmente compatível com os preconizados pela AAE. A participação, a comunicação, a disponibilidade de informação e a transparência nas decisões são princípios básicos para o sucesso da Avaliação Ambiental Estratégica.

A compatibilidade da Avaliação Ambiental Estratégica e o modelo de Gestão dos Recursos Hídricos, instalados no Brasil, podem ser também reconhecidos nas exigências legais de elaboração de Planos de Gestão dos Recursos Hídricos. As características de um planejamento estratégico exigidas na elaboração destes planos são, por concepção, coerentes, semelhantes e compatíveis com a Avaliação Ambiental Estratégica.

Objetivando informar estratégias de implementação da Diretiva de Introdução da AAE pelos países membros da União Europeia, em uma pesquisa liderada pelo Imperial College Consultants Ltd (ICON), publicada pela Comissão Europeia (2001), pode-se identificar quatro modelos de AAE, considerando países da União Europeia, fora da União Europeia e experiências financiadas pelo Banco Mundial:

- AAE inspirada na AIA: esta abordagem é inspirada na ecologia/gerenciamento de recursos naturais. Inclui uma avaliação de uma base de dados de uma opção pretendida. Existe mais ênfase em metodologias e a necessidade de um procedimento sistemático de avaliação. Esta forma é geralmente usada em nível de avaliação de programas. Geralmente é um incremento ao desenvolvimento da AIA.

- AAE inspirada em análise política: esta abordagem é originária das ciências políticas. Impactos de uma opção pretendida são analisados, considerando objetivos pré-estabelecidos. Não existe uma base de dados considerável e, geralmente, nenhuma ou pouca participação do público.

- AAE integrado: esta abordagem é focada em objetivos. É uma combinação dos dois primeiros modelos. Impactos, diretos e indiretos, são vistos considerando a combinação de uma base de dados 
ambientais e objetivos pré-estabelecidos. Este processo começa cedo no desenvolvimento de uma política, e a investigação de alternativas são meios para atingir os objetivos. A participação do público é geralmente um importante componente do processo. Esta forma é mais fácil de ser encontrada em países onde a legislação ambiental e a estrutura política são fortes.

- AAE com mecanismos ad hoc: instituições independentes são responsáveis pelo processo, com ferramentas e desempenhando de funções similares da AAE. Não existe, no entanto, um processo sistemático que possa prover raízes no desenvolvimento de políticas.

- Esta classificação é focada na origem dos tipos de AAE que existem atualmente. A pesquisa sugere que AAE pode ser vista como originária de duas principais ciências: gerenciamento de recursos naturais e ciências políticas. A pesquisa também indica que a melhor opção seria um processo híbrido entre as duas linhas. A Figura 3 demonstra, em forma de diagrama, a relação entre os quatro tipos de AAE.

Figura 3 - Relação entre os quatro tipos de AAE

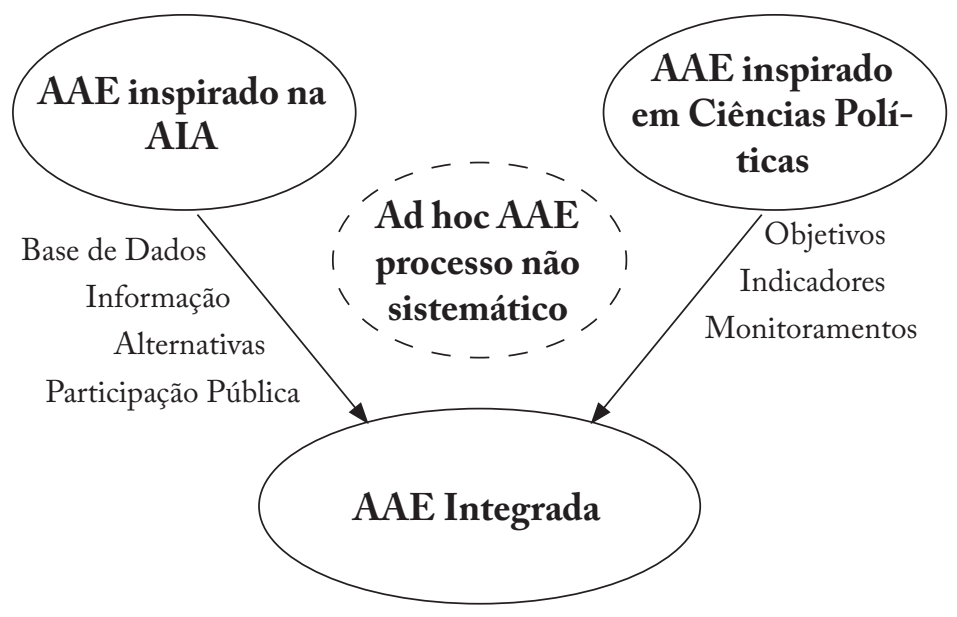

Fonte: ICON (2001).

Da análise geral das experiências, lições e recomendações podem ser retiradas. A grande recomendação é a busca por um processo de Avaliação que promova a integração do meio ambiente com as decisóes 
estratégicas. Segundo a pesquisa liderada pelo ICON (2001), esta busca deve acontecer:

1. No mais estratégico nível de decisão, considerando que a AAE deve ser vista como evolução e não revolução; é um processo sistemático, mas flexível e dinâmico; promove mudança de atitude e de cultura antes dos resultados; é um catalisador na integração do meio ambiente ao planejamento; é mais processo que metodologia.

2. Promovendo integração, considerando que AAE é uma abordagem continuada; auditoria, monitoramento e controle de qualidade são partes integrantes da AAE; eficácia da AAE é medida em longo prazo.

3. Com participação, considerando que as decisões devem ser transparentes e conjuntas; com o público e as autoridades pensando o mais estratégico possível.

4. A implementação da AAE deve considerar a necessária liderança e perspectiva estratégica; a necessidade de efetiva comunicação; trabalho interdisciplinar; qualidade da base de dados.

5. Orientações e treinamentos aumentam a consciência e as estratégias de comunicação; estimulam mecanismos de memória nas instituições; orientações promovem a efetiva integração do meio ambiente com as decisões estratégicas.

\section{Considerações Finais}

A busca constante pela sustentabilidade do desenvolvimento, onde os aspectos socioeconômicos e ambientais possam ser considerados de forma equilibrada, tem levado a criação e a evolução de instrumentos de planejamento e gestão.

A Avaliação Ambiental Estratégica, em particular para a gestão dos recursos hídricos, encontra na Lei das Águas um ambiente favorável para a sua introdução.

No entanto, os autores ressaltam os cuidados na introdução da Avaliação Ambiental Estratégica para um bom desempenho e o alcance dos objetivos de sustentabilidade.

Para o sucesso da AAE em direção a uma gestão integrada e participativa dos recursos hídricos, é necessária uma melhor articulação e coordenação das ações no setor de recursos hídricos e dos múltiplos 
usos. É necessário criar um ambiente integrador e fortalecer iniciativas de articulação intersetorial na busca de uma melhor coordenação na implementação das ações.

Esta articulação deverá ser mais forte nas regiões mais carentes, de modo a contribuir para a redução das desigualdades regionais. Assim para a região Nordeste e áreas menos desenvolvidas das regiões Norte e Centro-Oeste, esta ação é relativamente mais necessária, como forma de alavancar o capital institucional e social. 


\section{Referências}

AGÊNCIA NACIONAL DE ÁGUAS (Brasil). The Evolution of Water Management in Brazil. Brasília-DF, 2002a.

AGÊNCIA NACIONAL DE ÁGUAS. Evolução da Organização e Implementação da Gestão de Bacias no Brasil. In: CONFERÊNCIA INTERNACIONAL DE ÓRGÃOS DE BACIA, CIOB. Madri, 4 a 6 de Novembro de 2002, Anais... Madri, 2002b.

BRASIL. Ministério do Meio Ambiente. Lei das Águas - Lei 9433, de 8 de janeiro de 1997. Recursos Hídricos: conjunto de normas legais. 3. ed. Brasília: Ministério do Meio Ambiente/Secretaria de Recursos Hídricos, 2004.

CANADIAN ENVIRONMENTAL ASSESSMENT RESEARCH COUNCIL (CEARC). The Assessment of Cumulative Effects: A Research Prospectus. Supply and Services: Ottawa, 1988

CLARK, R. Making EIA Count in Decision-Making. Perspectives on Strategic Environmental Assessment. London: Lewis Publishers. CRC Press LLC, 2000.

CONSELHO NACIONAL DE MEIO AMBIENTE (CONAMA). Resolução 357 de 17 de março de 2005. Disponível em: <_www.mma.gov.br/ port/conama/res/res05/res35705.pdf>. Acesso em: 13 mar. 2011.

COSTA, J. F. Ação Administrativa - Consórcios Intermunicipais In:

DICAS, Instituto Polis, n. 111. 2001. Disponível em: < http://federativo. bndes.gov.br/dicas/D111.htm>. Acesso em: 03 mar. 2010.

CSIR. Council for Scientific and Industrial Research. Strategic

Environmental Assessment: A Primer, Stellenbosch, South Africa, 1996.

EUROPEAN COMMISSION, SEA and Integration of the Environment into Strategic Decision-Making. European Commission Contract $\mathrm{N}^{\circ}$ B4-3040/99/136634/Mar/B4, Final Report, May 2001.Disponivel em: $<$ http://ec.europa.eu/environment/eia/sea-studies-and-reports/sea_integration_xsum.pdf $>$. Acesso em: 13 mar. 2011. 
GARRIDO, R. J. S. Comentários sobre os aspectos institucionais do setor de Recursos Hídricos. In: CONSELHO NACIONAL DE RECURSOS HÍDRICOS. Artigos. Disponível em: <http://www.cnrh-srh.gov.br/artigos/ coment_garrido.htm > Acesso em: 01 abr. 2010.

\section{GLEICK, P. H. The World's Water. The Biennal Report on Freshwater}

Resources. Pacific Institute for Studies in Development, Environment and Security: Washington, Island Press, 2006.

\section{INTERNATIONAL ASSOCIATION FOR IMPACT ASSESSMENT} (IAIA). Strategic Environmental Assessment Performance Criteria. Special Publication Series, n.1, 2002.

IMPERIAL COLLEGE CONSULTANTS LTD (ICON). SEA and Integration of the Environment into Strategic Decision- Making European Commission Contract N ${ }^{\circ}$ B4-3040/99/136634/Mar/B4, Final Report, May 2001. Disponivel em: <http://ec.europa.eu/environment/eia/sea-studies-and -reports/sea_integration_xsum.pdf>.Acesso em: 13 mar. 2011.

MOREIRA, M. M. A. M.; SOUZA, R. C. R. Avaliação do Sistema Nacional de Gerenciamento de Recursos Hídricos no Brasil. In: SEMINÁRIO LATINO-AMERICANO DE POLÍTICAS PÚBLICAS EM RECURSOS HÍDRICOS, 1, 2004, Brasília. Anais... Brasília/ DF, 21 a 24 de setembro de 2004 .

MEMORIAL UNIVERSITY OF NEWFOUNLAND (MUN). Canada Environmental Impact Assessment. EA Concepts. Disponível em: < http:// www. ucs.mun.ca>. Acesso em: 27 ago. 2004.

SADLER, B.; VERHEEM, R. Strategic Environmental Assessment: Status, Challenges and Future Directions. Ministry of Housing Spatial Planning and the Environment, The Netherlands, and the International Study of Effectiveness of Environmental Assessment, 1996.

SCHREURS, P.; DEVUYST, D. Environmental Assessment in Belgium. EIA Newsletter, v.10, n.5-6, 1995.

VASCONCELOS, M. E. G. Avaliação Ambiental Estratégica: perspectivas e desafios na Gestão dos Recursos Hídricos. I SIMPÓSIO DE RECURSOS HÍDRICOS DO SUL. I SIMPÓSIO DE ÁGUAS DA 
AUGM. 1, 2005, Porto Alegre-RS, Anais... Porto Alegre, 20 a 23 de março de 2005.

VERHEEM, B. Strategic Environmental Assessment Performance Criteria. Special Publication Series, n. 1. International Association for Impact Assessment, 2002. 